\title{
Measurement of Affecting Factors on Jewelry Choice in Tehran
}

\author{
Samira Nikzad ${ }^{1}$, \\ Reza Afhami', \\ Aliasghaar Fahimifar ${ }^{3}$
}

\begin{abstract}
One of the production features in post-industrial era is diversified production capacity while maintaining the economic structure of production, which leads to variations in structure of design processes. The needs and preferences of customers shape production processes. As a result, measuring consumer behavior becomes important to design a product. This study aims to identify consumer behavior while choosing ornaments, especially jewelry, in Iran by determining the correlation between economic status and other independent variables, including sex, age, and ethnicity, on purchasing behavior. A field research, including a survey with 200 people, was conducted in Iran to find the consumer behavior. The results of questionnaire analysis remark effect of various variables such as different economic status, ethnicity and education level on expected concepts in jewelry and their symbolic use, where these results of model and image analyses are able to help us in production planning and jewelry design.
\end{abstract}

Keywords: Consumption, Ornament, Jewelry choice, Jewelry design, Audience-oriented design, Tehran.

\footnotetext{
${ }^{1}$ M.A. Student, Art research Faculty, Tarbiat Modares University, Tehran, Iran (s.nikzad37@gmail.com)

${ }^{2}$ Assistant Prof. Art research Faculty, Tarbiat Modares University, Tehran, Iran (Afhami@ modares.ac.ir)

${ }^{3}$ Assistant Prof. Art research Faculty, Tarbiat Modares University, Tehran, Iran
} 


\section{Introduction}

Behavioral design is an act, which during a special and conscious process and with the help of planning, responses subjectively to certain targets controlled and driven by designer. In a set of designs, including jewelry design, due to the variation in production processes, many components of major industrial design are less considered as ways of theme guiding. And by means of methods variety in contemporary era, dealing with audience-oriented methods are got necessary to serve as one of the ways of production in modern time and to respond to the changes of recent economic conditions in design.

Therefore, in current study in order to identify the behavior of jewels consumers in Iran and to determine the correlation between social status of consumption and consumer behavior towards design, the theories in both cases discussed firstly and behavioral theory of Bourdieu and Veblen are used. To make the Bourdieu's theory measurable, to examine social variables behavior a set of questions are considered and Kansei words are used for passionate association between the user and design. After distributing the questionnaires, results were analyzed by statistical analysis in different ways.

In the Middle Ages, the concept of consumption was significantly different from what is understood today. For majority of people, consumption was based on daily needs and survival, while among very few feudal lords and aristocrats were considered as greed and a way to get attention and present social status. But in eighteenth century, consumer capitalism were also established starting with early stages of industrialization, where resulted in rising growth of markets with domestic consumption and subsequently, new products and more choice options got presented to the consumer. Later, during nineteenth century, more wealth was distributed among the public and abundance and prosperity changed consumption patterns and played more fundamental role in people's lives and gave them opportunity to distinguish themselves from the other classes of society, while the products were more varied and also goods in size and quality got more diverse, consumption was not limited to the realm of upper class; since even workers with postal jobs joined the mass consumers' congregation (Timothy, 2009: 19-18).

In this process, initial concept of consumption based on immediate needs was changed and gained new forms so that secondary needs and fantasies got importance. In the process of social consumption, goods and services possess secret symbols, aside their natural qualities. 
In fact, social values and ideals considering respect and emotional needs are reflected in type of goods and people by acquisition of objects seize mentioned goods and redefine their social position. As well in Iran, spread of modernism associated with development of technology and facilities was followed by new patterns of daily living and lifestyle, where its nature was mixed with consumption quality of modern citizens (Varastefar and Mokhtari, 2009: 45-42).

Thorstein Veblen is the first sociologist who deals with new form of consumerism and its functions. He (2007) considers social motivation for competitive behavior and explores pecuniary emulation (an academic term for keeping up with the Joneses)_as the basis to explain the modern consumerism phenomenon and by proposing the Theory of the Leisure Class, represents the class distinction concept, which has found implication in consumption and brings up financial potency and wealth as the base of honor, dignity and social status. According to Veblen,
In every society, where organized industry is enhanced, financial capability is the most important underlying where the basis of reputation and reliability is based on and by means of leisure and affectation consumption of commodities, financial authority can be demonstrated and fame and respect are gained (Veblen, 2007: 22).

In his opinion, wealthy people try to exhibit their prosperity through conspicuous leisure in small communities and in urban and large communities, through conspicuous and affectation consumption.

Conspicuous consumption of leisure class ultimately affects everyone else in the stratification system, since people of every social class mimic leisure class behavior at peak point of stratification system to make decisions about what commodity they consume (Ritzer, 2010: 110; see also Simmel 1957 and Y1lmaz 2013).

Pierre Bourdieu is undoubtedly the most read sociologist who had spoken about consumption and lifestyle. The main idea of legacy of Bourdieu's for sociology of consumption and analysis of lifestyles is explaining the various types of the capital composition to identify consumption patterns, investigation of class division through consumption patterns and also is the basis of class style and cultural consumption (Fazeli, 2003: 34).

According to Bourdieu, consumption involves the use of signs, symbols, ideas and values and should not be analyzed as satisfaction of some biologically-rooted categories of needs (Bakak, 2002: 97). 
The link between social class and consumption behavior is studied in detail in his book of Distinction (1984). He conducts an investigation of consumption biases and cultural hierarchies of taste, by means of statistical measurement approach regarding the arrangement of people's social status in economic, social, cultural and symbolic capitals and according to "volume", "composition" and "path" of the capital and also "lifestyle", while he attempts to link specific lifestyles to social groups (Zokaei, 2012: 38).

People have different tastes and temperament, based on reserve and capital, thus people's tastes will be associated with their class. In other words, taste performs as a 'sign' in 'class'.

He believes that apart from some personally internalized and unique senses, taste is a social skill arises from education and training related to class (Jenkins, 2006: 215) and contrary of interests is concerned to the class conflict.

Bourdieu believes that social actors are influenced by past experiences possess semi-habits that are related to the insight, taste and judgment systems and enable them to perform their daily actions affected by practical knowledge (Momtaz, 2004: 154-157).

Surveys have shown that all cultural activities and also preferences and tastes in literature, painting or music firstly have close ties with education level and secondly with social origin (Bourdieu, 2011, 24).

\section{Methodology}

\subsection{Methodology and Research Objectives}

This study aims to achieve the ideal model to measure Iranians consumer behavior and use it as a tool for product design. The results of research can be used for design planning in components development of audience behavior measurement model. The overall objectives are as follows:

- Identify people's consumption behavior and its impact on field of jewelry

- Achieve a model for jewelry design planning

- Examine the relationship between consumption and jewelry choice

- Investigate the dependency of consumption components with selecting type of jewelry

- Observe the affiliation between economic variables and consumer behavior

- Obtain the correlation in gender type and consumption behavior 
- Study the nexus of literacy variable and consumer behavior

- Assess the relevancy between ethnicity variable and consumer behavior

\subsection{Assumptions and Theories}

In the present study, to determine the association between consumption and design T. Zhang's paper, two models of Maslow's pyramid of needs hierarchy and Social Theory of design by Town Kota have been employed. And for part of consumer behavior measurement, Bourdieu's theory of symbolic consumption and Veblen's social theory of consumption are handled, beside theory of Kansei engineering and its behavior measurement model has been applied in order to assess the emotional behavior of audience.

Current study has been performed by descriptive analytical method through survey and the objective is to make a link between design acceptance and consumer behavior of audience.

The research handles both literature and field study, including a questionnaire developed by the research fellow and field research was conducted quantitative. The questionnaire used in research is set and designed in two subject:

I. Independent and dependent variables in jewelry purchase.

II. Kansei engineering-based part.

It should be noted that among various jewelry, wedding ring has been selected for this study. The reason behind limiting the survey to wedding ring is since of being inconceivable to assess and identify the type and manner of whole consumption tendencies in all kinds of jewelry in one study in first, considering the fact that type of jewelry (ring, bracelet, earrings, etc.) is effective on style and choice and purchasing factors in one case cannot be applied for all other cases. And on the other hand, according to the ring's situation in Iranian culture, all people with any level of class inevitably purchase it and this actuality has a great impact in helping this study and approaches derived from it to be perceptible and applicable. Independent variables include factors such as, age, gender, education, region of residence, income and ethnicity. Questions related to the dependent variable contain explicit questions about how to choose goods as well as preferences about materials. Components applied in this section were collected with assistance of about 50 designers and jewelry sellers. Research instruments include literature survey and internet resources by taking notes manner and develop a questionnaire for field study. 
In following study, confidence coefficient of $95 \%$ is intended. In other words, five percent margin of error anticipated in calculating the results, beside amount of allowable error in estimation of a specific property is considered as $05 / 0$ percent. The descriptive statistics was applied for data interpretation and to determine levels of significance, ANOVA (Analysis of Variance), LSD (Least Significant Difference) and Games Howell tests were used. In part based on Kansei method, 300 words selected where after initial assessment tests 20 words finally remained, categorized in following 10 groups: Modern/classic, special/ mediocre, gentle/sophisticated, graceful/interesting, expensive/convenient, unique/fashionable, noble/fancy, stylish/luxurious \& gorgeous, courtly/cute, and simple/finery.

Above mentioned 10 groups were measured and rated by a seven-level scale of semantic differential and selected 12 pictures were attached at bottom of all of them. To explain selected images as well as their number, it is necessary to state that in order to avoid prolongation of amenability and assessor exhaustion which lead low accuracy, number of shots limited to include only to cover the most desired features.

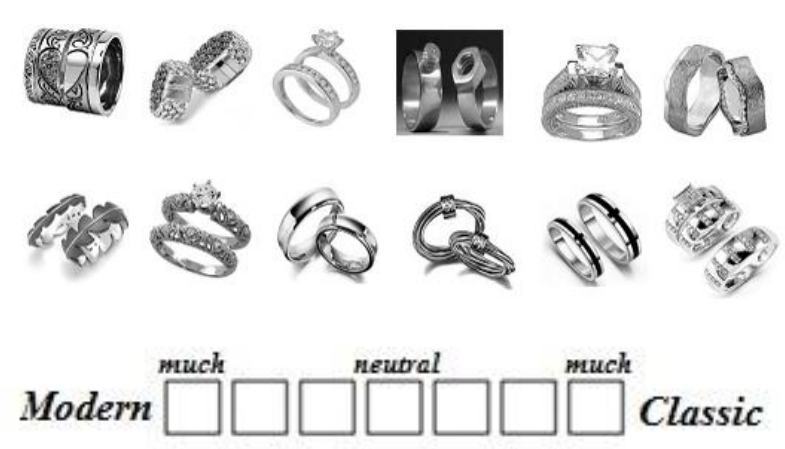

Figure 1: The seven-level semantic differentiation and selected images to measure audience Kansei

\subsection{The Method of Selection and Number of Samples}

In order to sample selection multi-stage cluster method is utilized, dividing Tehran city into five zones of Central, North, South, East and West, where telephones of 10 recent costumers were provided through 20 jewelry shops and after contacting them, thereafter questionnaires were filled out in three ways via email, phone call and meeting personally on jewelry shop and finally using statistical software conclusions were analyzed. The sample size was determined by the following formula:

$n=\frac{(1.96)^{2}(0.25)}{(0.07)^{2}}=200$ 


\subsection{Data Analysis}

Analysis performed by using the SPSS software, including analysis of the results obtained from questionnaire and its implementation separately with Bourdieu and Veblen's consumer theories and theory of Kansei. Finally results were examined, in order to determine person consumption behavior based on independent variables and also to identify design examples based on Kansei and emotional components, the updated model has been investigated.

\section{Theoretical Foundation}

\subsection{Relationship Between Consumption and Design}

In this section regarding to the Maslow's Pyramid of Needs the connection between human need levels and mode of consumption patterns will be determined and thereafter, based on Küthe's "design and society" model, design styles and trends formation and their characteristics impressed by different social conditions in various decades will be investigated.

Human needs considered as a relatively mental and cultural concept by economists, sociologists, philosophers and social critics and the best-known model for human needs proposed in 1945 by Abraham Maslow in a paper titled A Theory of Human Motivation (Figure 1). Maslow describes human needs by a pyramid consisting of five levels in his theory.

Maslow's hierarchy of needs consists of "physiological" at the base of pyramid, where is followed by "safety", "belongingness and love" and "esteem" also mentioned as basic needs. The highest level of the pyramid is called "self-actualization" that is also interpreted as "selffulfillment".

Later, Maslow (1993: 150) divides self-actualization needs and locates two levels of "cognitive" and "aesthetics" needs which are also sometimes referred as spiritual needs in higher level of pyramid, before than self-actualization and self- fulfillment level (Zhang and Dong, 2008: 4). 


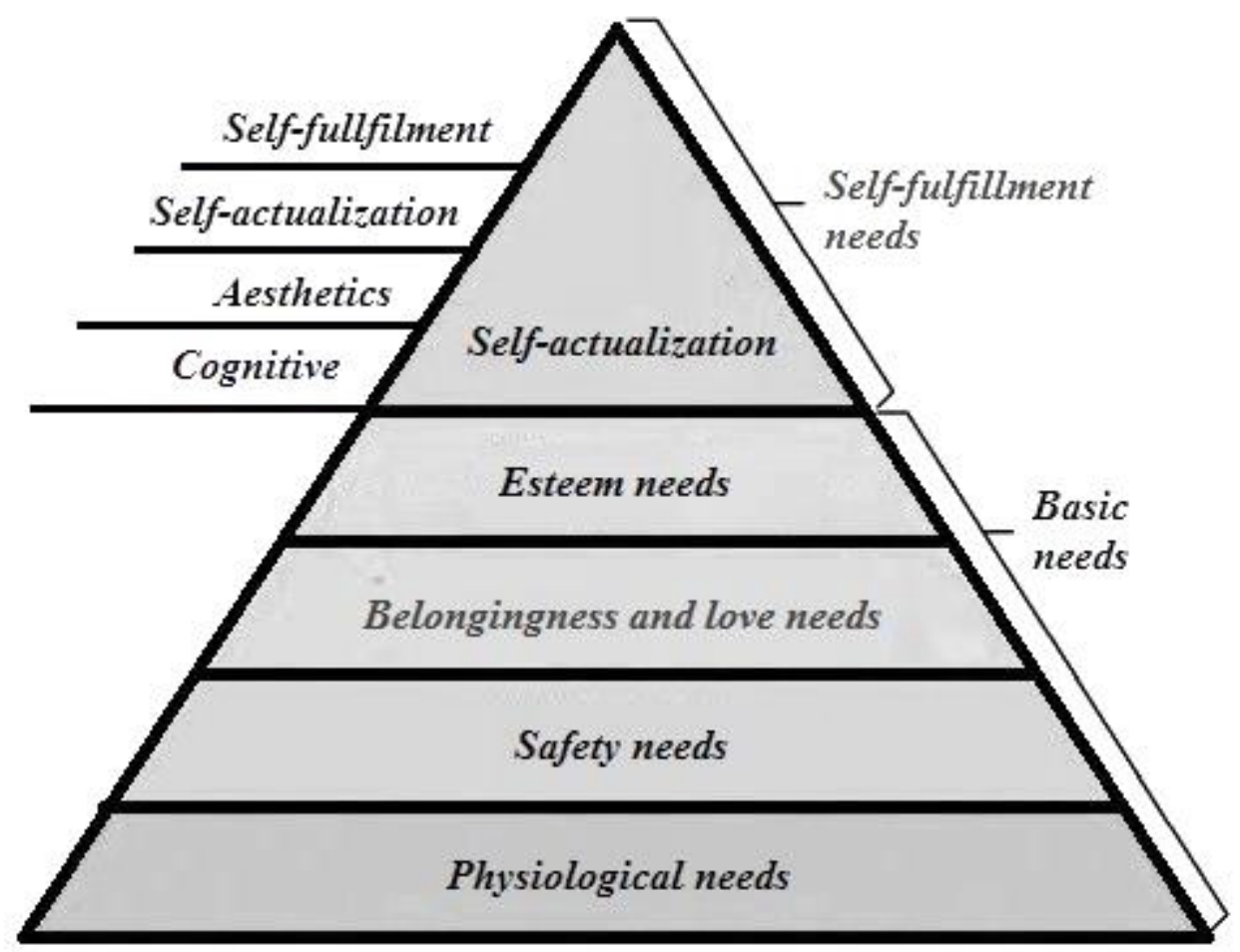

Figure 2: Maslow's pyramid (Anthropology.ir, 2013/09/11)

Maslow believes that people behavior in certain moments is affected by the most severe needs. When need satisfaction begins, a change will occur in person motivation so that another level of need will get importance instead of previous needs and will drive the behavior. Needs will take off until meeting the peak of hierarchy of needs' pyramid and will subside after satisfaction and shift the turn for other (Farsi Wikipedia, 02/05/2014).

Therefore, by alternation of people needs from one level to another, type of consumption and consumer behavior cause and quality will change and the design should be able to respond all these changes and consider them in process of ideation and product design (Zhang, 2008: 4).

\subsection{Model for Design and Society}

In his "design and society" model, Küthe explains how a design finds its own characteristics and trends in each period according to the level of welfare and social view governing on society (Figure 2-3). He divides design history of twentieth century's second half into five periods:

- $\quad 1950$ s - growing society: styling was the main design tendency;

- $\quad 1960$ s - mature society: design focused on function and use worth;

- $\quad 1970$ s - saturated society: aesthetics was the keyword of design; 
- $\quad$ 1980s - society of superfluity: design explored semantics;

- 1990 s - society of satiety: design was about self-presentation and experiential design.

Prior to the 1950s: design focused on more performance. Common slogan of that time was "appearance follows the function" that was reflecting such thinking in design.

- 1950s - 1980s decades: during this commercial and industrial period, consumer-based designs appeared. Main tendencies during this period include: appearance design, usage value, aesthetics and semantics. Although some phenomena such as "planned obsolescence" focused on consumption, consumers' needs and objectives are major basis of humanistic thinking in this period.

- Up to the present time: design considers greater emphasis on human, but not only as consumers or users. From the 1990s so far, products have got increasingly smaller and smarter, even that sometimes it seems difficult to understand and interact with them. As a result, researches on abilities and human-oriented ergonomic designs have emerged. Humancomputer interaction has begun to influence other design fields. The concept of humanoriented design is growing day-by-day. Firms such as IDEO, P\&G, and Apple have adopted human-oriented approaches in their design process.

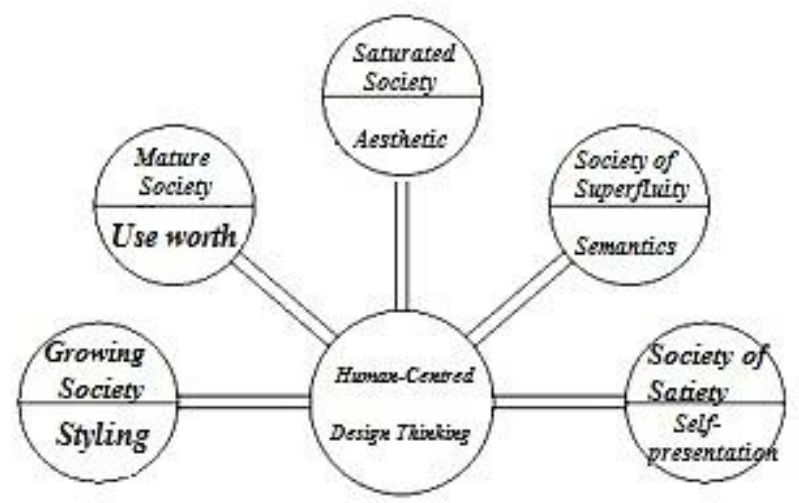

Figure 2-3. Küthe's "Design and society" model (a Brief History of Design)

Maslow's model is presented from the small and psychological point of view, despite Küthe's model is proposed in terms of macro and social perspective. By combining the two models, a conceptual model is obtained that interacts between human needs and design evolution.

On the left side of hierarchy of needs pyramid model, human needs as physiological, security, belongingness, esteem and self-actualization needs are located: 
- In performance-based period, design attempts to produce products and services that satisfy fundamental levels of needs like physiological and security.

- In an era of focusing on consumer, design is moving towards applicable and useful solutions at the same time. Belongingness and esteem needs were considered for making decisions by designers.

- In human-oriented period, design is willing to meet higher levels of needs. Nowadays, product performance and functionality is not enough alone. Products have to respond higher levels of human needs. Needs of self-actualization including cognitive, aesthetic, selfactualization and self-fulfillment are required for future designs to tend toward them. (Zhang, 2008: 5-4)

\subsection{Kansei Engineering}

The psychological aspects of design are increasingly taken into consideration recently. In this case, there is a general consensus that in a competitive market, where products are desired objects, something beyond the form and their function must be expected. For this purpose, the product should be used either for pleasure of using or because of facial aesthetic, to provide pleasant sense of correspondence with final users.

In the books of many designers, emotivism is not only a powerful and essential method to make a deep and semantic relation between product and user, but also an efficient tool for them to distinguish their solutions from their competitors.

In other words, regarding to consumer sentiment to create a human-based design leads to compelling and attractive appearance of product. Knowing the fact that emotion base of a design could achieve final accomplishment, user satisfaction by beloved product is as important as his satisfaction by needed product. Conclusively, creativity in new design should be sensitive to usage patterns and react to them (Sarvari, 2009: 194-158).

Due to this new situation, customers' expectations and demands changes. More people want to express their individuality. Even products provided by mass production should be in terms of shape, design and function compatible with individual demands, thus to extract the consumers' needs is one of the biggest challenges forcing the design team.

In an attempt to understand the wants and needs of customers, several methods have been developed such as the "Voice of the customers" (Griffin and Hauser, 1993), "The Kano 
Model" (Kano et al., 1984), "Affective design" (Helander and Khalid, 2004), "Human factors design" (Park and Han, 2004) and "Kansei Engineering" (Nagamachi, 1970) (Tarantino, 2008: 11). Among these methods, Kansei Engineering (KE) benefits of a strong structured process for analyzing unexpressed and unconscious needs of consumers to restore their need to design field (Nagamachi, 2008: 292).

Kansei Engineering is a method to form the feelings and emotional effects as productivity parameters, which is able to measure various feelings and indicate their relevancy with products characteristics. As a result, it is feasible that products are designed to offer emotions and feeling conditions (Grimsaeth, 2005).

The purpose of Kansei engineering is to measure the quantity of consumer emotional response (Kansei of consumer) and connect it to the product parameters, where this approach is applicable to improve any goods such as mobile phones, office and home furniture, packing, cars, road and construction machinery and fashion product (Nagamachi, 1995: 4).

\section{Theories:}

-Consumption patterns and transformation of products into cultural prosperity are important in determining the design variables in field of jewelry design.

-Compliance of social factors and emotional reflections of consumption is able to become a tool for design planning in a structuralism approach

\section{Results and Observations}

In terms of education level, the majority of respondents had a bachelor's degree and in the case of location and accommodation region, an attempt done to choose attendants from all urban parts of Tehran city. Covering regions of city were so close, however the major respondents ranked from south, west, north and central parts of Tehran. Beside, ranges of 1 to 1.5 million, 1.5 to 2 million, more than 2 million and finally 500 thousand Tomans were rated as main attendants' salaries respectively, where the most salary range lies between 500 thousand and 1 million Tomans per month. Most of the respondents were Turkic ethnic and people from Persian, Northern Iran, Luri, Kurdish, Arab and Turkmen were the highest ethnics, respectively. 


\subsection{Gender-Related Dependent Variables}

As can be seen, slightly different behavior of two genders is observed. In general consumer behavior, men are more inclined to impose their taste, while women often have more reasonable behavior toward a ring purchase, where major tendency is toward to impose personal taste.

Comparing two genders, significant difference in terms of ring purchase was not realized in choosing of first and sixth priority, unlike the considerable variety in choice of other priorities. Men's priority to buy a ring is rated in terms of personal taste, spouse opinion, financial condition, ring design, family comment, relative purchase and brand design, while women are choosing rings based on priority of financial condition, personal taste, spouse opinion, desired design, brand design, family comment and relative purchase.

Regarding two genders, in terms of ring type choosing any significant difference was not observed in second to sixth priority, unlike the semantic difference in choosing first priority.

Men's priority to choose a ring type is ranked consisted of white, matte yellow, shiny and matte yellow, matte yellow and platina, while women are choosing ring type in priority of white, matte yellow, silver, matte yellow and shiny yellow. In comparison between genders, in terms of color of ornamental rock considerable differences were not found in priorities first, second, fourth, fifth and sixth, unlike the third and seventh priorities.

In choice of ornamental rock color, men's priority is based on colors such white, green, blue, purple, yellow and black; while women have chosen white, green, red, purple, blue, red and yellow, respectively. Both genders have preferred white and matte yellow colors respectively, and most tendencies in color of ornamental stones were toward to diamonds and emeralds. Although in case of women, rubies have the next highest priority, where men behave differently in selecting cold colors. In terms of shape of ornamental stones, considerable differences were not observed in any priorities of first up to fifth, comparing two genders. Men and women have chosen amorphous-shaped, round, marquis, baguettes and irregular shapes of ornamental stones, in priority and irregular stones and then rounded ones have been considered.

Men mainly prefer to purchase available designs from abroad and women consider personal taste and then foreign designs. Men have little interest in stone and both sexes prefer the classic design, but in all cases, nobody follows good value and expensiveness. In addition, men are more likely to be subtle while women have not shown a certain tendency. 


\subsection{Dependent Variables Related to Education Level}

Talking about education, general factor is personal taste, but focusing on financial condition increases in case of higher education which remarks increment of reasonable behavior in purchase. Observing the correlation between education and ring purchasing, relation appears in terms of first, fifth and sixth priorities. Purchase a brand design is highest priority in all groups categorized by academic level, except for people with master's degree, knowing that these people gave the last priority to relatives purchase.

Regarding the relationship between education and ring type, first, second and fourth priorities are related to level of education. The general tendency is toward white color, unlike in case of higher-level education tendency to yellow, which means less impact of fashion on this group. Also statistical significance observed between education and color of ornamental stone in first and sixth priorities. Obtained results of this section reveals the tendency toward white and light colors in case of higher levels, while pretentious and jeweled (pearl) colors get desired more in lower levels of education

In two cases of stone and design type did not observed any significance correlation and results show that most of respondents have chosen irregular stone in the first and last priority and the most preferred complied with personal taste, which is the first priority of 50 percent of total attendants. And acquaintances' rings and cases in foreign movies are located at least degree of importance of fifth and fourth priority place, respectively.

Assessing the dependency of education and Kansei words has remarked that by being special or mediocre, graceful or interesting, noble or fancy, stylish or luxurious and courtly or cute, there is a significant level of relevancy. Considering a ring being whether special or mediocre, statistical signifiers were observed among education groups of high school diploma with associate degree, bachelor and Ph.D. degrees; while by investigating the purchase of whether graceful or interesting ring, correlation among the groups of high school diploma with associate degree, beside masters with associate and bachelor degrees was apperceived. Howbeit in original/fantasy rings confrontation, connection was noticed among the groups of masters with associate degree, bachelor and masters. Nevertheless, stylish/luxury examination revealed relation among the bachelor group with high school diploma group, aside associate degree and masters group with high school diploma, and also associate degree and Ph.D. categories with bachelor and master groups. Getting high education, the attention toward classic and graceful forms increased and tendency to be stylish confronts with being luxurious, where all categories prefer to have a courtly product. 


\subsection{Dependent Variables Related to İncome}

The results show that in terms of fifth and seventh priorities of relevancy between money and ring purchase, there is a statistical significance. In comparison among the different groups of income range, correlation was observed in fifth priority among the 1-to-1.5 million monthly income group with less than 500 thousand and 500 thousand to 1million income groups, and also among the monthly salary groups of greater than 2 million with less than 500 thousand and 500 thousand to 1 million Tomans monthly salary groups. Although relevacy was noticed in seventh priority among the income groups of greater than 2 million Tomans with less than 500 thousand, 500 thousand to 1 million, 1 -to- 1.5 million and 1.5 to 2 million.

In the case of income variable, no result was achieved in first priority, but tendency to apply the personal taste got more importance and financial condition is less important for people. This means that in community a form of personal expression behavior is emerged compliant to Küthe's pattern and a kind of self-sufficiency is considered in selection process, where financial issues are under consideration. The relationship between income and ring type was found in second and fourth priorities.

Major desire toward white color shows the behavior in society in accordance with frequent practice, although however yellow colors especially the shiny ones are not found among priorities. Talking about ornamental stones, the sixth and seventh priorities are related and overall, the general regard has been toward diamond and brilliant and then stones such as emerald, respectively. The use of stones with irregular form among people with lower incomes and the usual round form among people with higher income implies the visible influence of fashion within the community. As regards to chosen ring design associated with income, relationship was noticed in third, fourth and fifth priorities.

For people with higher salary can be concluded that they are less concerned about their personal tastes and mostly prefer established available forms and have less propensity to make an expensive jewelry purchase. Finally, the use of existing designs and influenced by foreign mass media are visible in next priorities of entire community. By investigation of relationship between income and Kansei words in, in terms of special/mediocre, gentle/sophisticated, unique/fashionable, noble/fancy, stylish/luxurious and courtly/cute, a correlation was perceived. The overall result showed that there are two general categories in entire society based on emotions, whereof people with lower income prefer modern or less classic cases, while the classic cases are more desired by rising incomes. Most of attendants prefer distinguishable and unique jewelry, beside look for nobility and stylish products. And public 
taste is to choose an elegant and durable design and less propensity to accept fashion in consumption, due to the cost, expenditure durability and consumption duration.

\subsection{Dependent Variables Related to Living Region}

Another considered variable beside the income is living region's variable, which is imperceptibly being covered in concept of income. Make a ring purchase and living region are in relation in terms of fourth and sixth priorities. The relationship is observed in fourth priority, between the groups of high school diploma and advanced diploma, advanced diploma and Ph.D., where in fifth priority between the groups of west and east regions and finally, in sixth priority between the groups of south and central, west and north, and also central and east regions.

The results show that people from north region of city more interested in personal consumption and ring design and in their opinion taste, and also financial condition is an important factor in choice of ring. While in the south area, criteria of people around and relatives are more important for selection, which indicates that these people tend to have been rivalry with others.

Also a correlation noticed about the ring material, in second and fifth priorities, which in second priority, observed among the central region with north and south, east region with north and also west region with north and south, while in fifth priority considered among the groups of south and center. General prefer in east and south of Tehran is toward precious metals like platinum and yellow opaque. Also in purchase of material type, duplication of public behavior was observed, however, most people tend to display jewelry through the color by second preference, rather than price increment and material value of jewelry. And about the color and form of stones there is a public taste that everyone follows.

In most areas of the city, people have the chance to choice between personal taste and foreign designs. But in south, east and central region tendency to foreign models and non-Iranian movies plays an important role in determining the consumer behavior. To investigate the ornamental stones in rings is a priority in east Tehran, while in other areas there is no such a priority. In south and east more propensity to be special was noticed, unlike the North and West, which means less needed feel to be distinguished in mentioned areas. However, being fashionable takes place in northern regions, while in other parts being unique is more paid attention. 


\section{Dependent Variables Related to Age}

The relevancy of this factor are found as follows: Fourth and seventh priority in buying the ring and age; second priority and third in ring purchase and age; first, second, sixth and seventh priorities in colors of stone and age; first, fourth and fifth priorities in form of stone and age; third and fourth priorities in ring design and age, unique or fashionable, noble or fancy, stylish or luxurious, simple or sophisticated and courtly or cute and age. In the case of age variable, tend more toward taste than financial conditions, while financial conditions and spouse impact is more considerable in early ages. In all cases, any tendency toward a brand or design cannot be seen which means that we are not faced with a creative use by increased age. Inclination increases to use more yellow jewelry, in older ages, beside tendency to use more rubies and less fancy colors is visibly observed. Desire to use more regular stones are associated with increased age and also in older ages choosing the existing and foreign schemes is more considered and less attention is given to personal designs and relatives' comments. In addition, desire of uniqueness have been raised up by aging, where classic designs got less attention and also less-sophisticated, stylish and dignified products are more considered.

\section{Dependent Variables Related to Ethnicity}

The most important factor is still ethnic attitudes to purchase, which plays an important role. The survey shows statistically significant results in terms of second priority of ring purchase and ethnicity; first, second and fourth priorities of gender and ethnicity; second, third, fifth and sixth priorities of ornamental stone color and ethnicity; first and second priorities of ornamental stones form and ethnicity; and first, second and fifth priorities of ring design and ethnicity. Also relationship between ethnicity and Kansei words shows considerable significances.

In all ethnic groups, tendency toward an ornamental stone in the ring was low or very low. The Lak respondents desired courtly, special and elegant rings, respectively, while their tendency toward the adjectives such expensive-convenient, noble-fancy and gentlesophisticated has been neutralized. People of Persian ethnic show behaviors based on financial conditions, while the Kurds, Lurs, Turks and Laks are more subjected to their personal taste and the other ethnics consider more attention to relatives comment. 
There is a general tendency toward white color, among these people; however, Baluch and Arab people prefer more expensive and platinum products, while other ethnics have chosen opaque yellow color. Among the all ethnic groups, there is a diamond and emerald taste, while Kurds, Laks and Lurs mostly prefer more fancy colors, unlike red. However, the color change is less desired by Arabs and Baluch people. Irregular stone and then rounded form are preferred generally by all ethnics, except than Turkmen, Northern people and Turks which tend to round stones, beside other form of stones are less desired to be considered. In all ethnics, following the personal taste, the adaptation of foreign designs and existing schemes is important in second order. Ornamental stones in jewelry do not much get attention, but general tendency is to purchase the graceful and special jewelry, except than northern people and Turkmens who prefer interesting jewelry products. Turks pay more attention to the price of jewelry; while Kurds, Laks and Lurs prefer more fashionable rings. Turks prefer sophisticated, where Turks and Baluchis desire gentle works. Baluch-Arab communities and Persians are less likely to be dignified, unlike Turks care about this issue.

\section{Conclusion}

The current study aimed to investigate the ways of jewelry consumption in Tehran. The results suggest that a kind of consumerism based on symbolic budget and pretentious consumption in Iranian society and especially among the middle classes and lower income groups is growing. In addition, the mentioned group tend to have a kind of personal consumption and less heed to reflection of their behavior, unless the cases concerned with social reflection and particularly being special. There is little evidence of creative consumption and not able to say that we face a society with conscious consumerism who wants to reflect its development in jewelry. Impacts of education and age on behavior change only make sense in rationalism and do not certain effect on changing tastes. Regarding ethnicity, personal taste is the most significant factor for Laks, Lurs and Kurds. In the case of Persians, its effect is mild. Regarding Turks, the value of goods, and for Baluch and Arab ethnics, expensive and elegance consumerism are respectively important.

But many of the components of all ethnicities and age groups and education levels are identified by public behavior and general trend that represents a type of fashion-acceptance consumption in entire cases. These are the factors that in designing of approved products can be applied. An ability can be proven to some extent which is provided to identify a type of specific behavior of the target population, that can be took into account as influencing factors 
on design. As regarding the factors of Kansei words concerned with ethnicity are prominent in this study, in order to create a more efficient model design, it is firstly necessary the cases related to meanings of Kansei words to be investigated in visual culture of ethnic groups, henceforward to establish a more accurate structure-oriented model on the basis of mentioned investigation.

\section{References}

Bakak, Robert (2002). “Consumption”. Translated by Khosrow Sabri. Tehran: Shirazeh Publications.

Bourdieu, Pierre (2009). "Distinction: A social critique of judgments of taste". Translated by Hassan Chavoshian. Tehran: Sales Publications.

Timothy, J. Dalen (2009). "The sociology of consumption (tourism and shopping)". Translated by Ali Asghar Saeedi and M. Hossein Abadi [Tehran]: Jame-e shenasan Publications.

Jenkins, Richard (2006). “Pierre Bourdieu”. Translated by Leila Jowafshany and Hassan Chavoshian. Tehran: Ney Publications

Zokaei, Mohammad Saeed (2012). "Leisure, consumption and society; critical speech". Tehran: Tisa Publications.

Ritzer, George (2010). “Contemporary sociological theory”. Translated by M. Salasi [Tehran]: Elmi Publications.

Sarvari, Saloume (2009). "Design on the passage of time; industrial design, architecture, art and design history". Tehran: Jahan-e Now Publications.

Fazeli, Mohammad (2003). "Consumption and lifestyle". Tehran: Sobh-e Sadegh Publication

Maslow, Abraham. H. (1993). "motivation and personality”. Translated by Ahmad Rezwan Mashhad: Astan-e Qods-e Razavi Publications.

Momtaz, F. (2004). "To introduce the concept of class from the perspective of Bourdieu". Journal of Human Sciences: 42-41. Spring and summer 2004: 160-149.

Varastefar, A. and Mokhtari, H. (2009). "The pattern of consumption among women of Tehran" Journal of Pajuhesh-e Ejtemaee. Winter 2009: 62-41. 
Veblen, Thorstein (2007). "Leisure class theory". Translated by ministry of Culture, with an introduction by C. Wright Mills. Tehran: Ney Publications.

Grimsaeth, K. (2005). "Kansei Engineering”. Times [online] 10 january. Available from www.ivt.ntnu.no.

Nagamachi, M. (1995). Kansei Engineering: “A new ergonomic consumer-oriented technology for product development”. International Journal of Industrial Ergonomics 15, pp 3-11.

Nagamachi, M. (2008). "Perspectives and the new trend of Kansei/affective Engineering". The TQM Journal, 20(4): pp 290-298.

Tarantino, P. (2008). “A Statistical Thinking Approach to Kansei Engineering for Product Innovation". PhD. Thesis, University of Naples Federico II.

Zhang, T \& Dong, H. (2008). "Human-centre design: an emergent conceptual model”. In Royal College of Art, April 8-10, 2009. London: Include2009 proceedings.

Simmel, Georg. (1957). “Fashion.” American Journal of Sociology. 62:1, pp.541-

Y1lmaz, Selman (2013). "Cultural Muslims: Popular Religiosity among Teachers in Public Elementary Schools in Turkey.” Journal of History, Culture and Art Research. 2:3, pp.237258. 